\title{
Knitting while Australia burns
}

To the Editor - A global biodiversity hotspot, Australia has reached a tipping point from which many of its forests may never recover. Record-breaking heat, drought and windy conditions have burned at least 10 million hectares. Halfway through the season, fires have persisted for months with no end in sight. The continent faces an exponential rise in future wildfire risk as the climate warms and dries.

Although many of Australia's ecosystems are adapted to historical wildfire, changes in the wildfire regime will transform the landscape and fauna. For example, as fires return more often, up to $10-20 \%$ of wet sclerophyll forests, with their iconic tall eucalypts and unique fauna, are projected to become dry scrublands ${ }^{1,2}$.

One might expect that a global crisis that will forever reshape the ecology of the Australian continent would stimulate a collective commitment to reduce greenhouse gas emissions worldwide. Instead, the world has responded with a global effort to knit, crochet and sew booties, koala mittens, joey pouches and even nests for rescued wildlife. According to Reuters ${ }^{3}$, "Knitting needles are clicking furiously around the world to create hundreds of protective pouches and blankets for native wildlife made homeless by Australian wildfires that have razed large swathes of bushland." For those with a strong desire to help, the opportunity to rescue Australia's charismatic megafauna - large species with widespread popular appeal such as cuddly koalas - by crafting items for rescued wildlife has motivated many to pitch in.

Clearly the knitting movement demonstrates the global scale of public interest in helping Australia's fauna. Sadly, animals may be injured or killed directly by smoke inhalation or burning, or indirectly by starvation or predation in the open, burned landscape. But the rescue of individual injured animals cannot ensure their survival, let alone the persistence of species. After burning, the habitat required to support rescued animals no longer exists, and there is no alternative except to euthanize many animals. At the population level, when large areas are burned, species with small geographical ranges lack unburned refugia where they can reproduce so that populations can grow and later recolonize burned areas. For example, species endemic to Kangaroo Island, such as the dunnart and glossy-

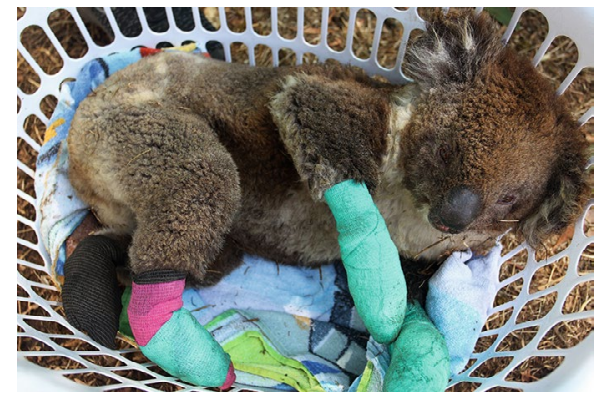

Credit: Lisa Maree Williams / Stringer / Getty Images News / Getty

black cockatoo ${ }^{4}$, have had one-third of their habitat wiped out by recent fires. The southern corrobee frog and silver-headed antechinus face similar risks because they inhabit elevational 'islands'. The closest unburned montane habitat may be too far away to recolonize the burned area. A large proportion of Australia's threatened and endangered species are forest specialist $s^{5}$ (for example, yellow-bellied and greater gliders, long-footed potoroo and regent's honeyeater), including arboreal species that are particularly vulnerable to fire. Because of their limited gap-crossing abilities, these species require a continuous canopy unbroken by fire.

Thus, there is a scale mismatch between small-scale rehabilitation efforts targeting injured animals and the broad-scale climate adaptations that are needed to reduce the number of species extirpations.

Maintaining Australia's existing ecosystems and species can only be achieved by moving toward a carbon-neutral economy before biodiversity hotspots like Australia lose more species. Meanwhile, climate adaptation is needed to manage bushfires and help wildlife to find remnant habitats that shift in time and space. Surprisingly, wildfire projections have not been incorporated into Australia's climate adaptation plans ${ }^{6}$. Short-term mitigation options include protecting unburned remnants as refuge areas by minimizing other threats (such as predation by feral cats) and providing assisted migration to these refuges. Promoting vegetation recovery is another short-term option, for example through aerial seeding of eucalyptus forests after the seeds are destroyed by crown fires ${ }^{7}$.

Active management to increase the interval between fires is one mid-term adaptation strategy. Where fire is limited by fuel (for example trees) and not fuel moisture (drought) ${ }^{8}$, this can be achieved by scheduling prescribed burning and thinning treatments $s^{6}$. Many forest species require long-unburned forest ${ }^{9}$, and even species that inhabit more-open habitats require unburned refuges and sufficient time to recover between fires ${ }^{10}$. In some ecosystems, species vary in preferences for intermediate seral stages, and these can coexist in a 'pyrodiverse' mosaic with varied times since burn. The hope is that such temporizing measures will provide at-risk species with habitat until climate trends can be partially reversed.

Although headlines about joey pouches and koala mittens may seem to trivialize the problem in the public eye, they also demonstrate widespread global support for addressing climate threats to biodiversity. These threats are neither trivial nor local, as similar wildfire-induced forest losses are expected in the Amazon and western North America. There are no 'band-aid' solutions, knitted or otherwise. Moving quickly toward a carbon-neutral economy and developing climate adaptation plans that consider wildfire should be priorities knitted into the fabric of government, industry and individual decisions worldwide.

\section{Henriette I. Jager (iD ${ }^{1 *}$ and Charles C. Coutant ${ }^{2}$ \\ ${ }^{1}$ Oak Ridge National Laboratory, Oak Ridge, TN, USA. ${ }^{2}$ Oak Ridge National Laboratory, retired, Oak Ridge, TN, USA. \\ *e-mail: jagerhi@ornl.gov}

Published online: 24 February 2020 https://doi.org/10.1038/s41558-020-0710-7

References

1. Cawson, J. G., Duff, T. J., Swan, M. H. \& Penman, T. D. Ecosphere 9, e02211 (2018).

2. Fairman, T. A., Bennett, L. T. \& Nitschke, C. R. J. Environ. Manage. 231, 59-65 (2019).

3. Wardell, J. \& Sanusi, N. A. Reuters (6 January 2020); www.go.nature.com/2tMoDJv

4. Taylor, A. H. The Atlantic (9 January 2020); www.go.nature. com/2Rq9QND

5. Davey, S. M. Aust. For. 81, 214-230 (2018).

6. Williams, R. J. et al. Interactions Between Climate Change, Fire Regimes, and Biodiversity in Australia: A Preliminary Assessment (CSIRO, 2009).

7. Bradstock, R. A. et al. J. Environ. Manage. 105, 66-75 (2012).

8. Cawson, J. G., Duff, T. J., Swan, M. H. \& Penman, T. D. Ecosphere 9, e02211 (2018).

9. Prowse, T. A. A. et al. Biol. Conserv. 215, 268-276 (2017).

10. Crowther, M. S., Tulloch, A. I., Letnic, M., Greenville, A. C. \& Dickman, C. R. J. Mammal. 99, 416-427 (2018). 